EDWARD M. GRAMLICH

The University of Michigan

\title{
Macro Policy Responses to Price Shocks
}

IN RECENT YEARS the standard view of the inflation process has become complicated by the realization that inflationary bursts can emanate from supply as well as from demand disturbances. Supply-side disturbances, reflected mainly in rising food and oil prices, generated sharp increases in general price levels in most countries of the world during the 1973-75 period. The impact in the United States was magnified by wage-price catch-ups after the ending of controls, the productivity slowdown, the decline in the dollar, and a number of legislative measures resulting in higher costs and prices. More recently, the decline of oil production in Iran and rising farm prices are kindling fears of new supply-shock inflation.

Price shocks from the supply side differ from traditional demand-pull disturbances because they can occur even at low levels of aggregate demand. Indeed, both theory and data suggest that supply shocks are more likely to be associated with recessions than with booms. Because this is so, standard remedies for dealing with supply-side inflation are not readily apparent. Most economists now more or less agree that aggregate demand policy should not permit unemployment to fall below its natural, or nonaccelerating-inflation, rate for any length of time. But whether unemployment should be allowed to rise above its natural rate in the presence of a

NOTE: I have benefited from the insightful comments of several BPEA participants, especially from discussions with William Fellner, and comments on a draft by University of Michigan colleagues Gardner Ackley, Robert S. Holbrook, Saul H. Hymans, George E. Johnson, and William S. Krasker. I would also like to thank Susan Albert, Gregory Dow, and Judith Pregulman for their highly competent research assistance. 
price shock from the supply side-and by how much and for how longis a much more difficult question. At one extreme, macro policy could "accommodate" the shock, using either monetary or fiscal policy to shift the aggregate demand schedule in an expansionary direction, maintain unemployment at its initial rate, and accept whatever inflation might ensue in the process. At the other extreme, monetary and fiscal policy could be used in an attempt to engineer a recession sufficiently deep to extinguish the shock-induced inflation promptly. Somewhere in the middle would be a class of macro policies aimed at a constant or adjusted growth path for nominal income. Under these compromise policies the higher price levels induced by the shock (when spending demands are inelastic) will imply a temporary period of both unemployment and inflation, lasting until the higher unemployment sufficiently reduces wage and price levels throughout the economy to permit a return to the preshock unemployment rate. The choice between policies depends on whether the social costs of the greater inflation generated or permitted by the accommodating macro policy outweigh the social costs of the greater inflation and unemployment generated by any of the nonaccommodating strategies. Ironically, this raises the old question of how to choose between more inflation and more unemployment, even in a view of the inflation process that may allow no long-term trade-off between the two.

In this paper I analyze and compare these policy choices. The aim is to summarize and pinpoint the implications of various models of supply shocks and the inflationary process, without advancing a particular point of view. The paper begins with a review of two recent models of supplyshock price increases, one developed by Gordon and one by Phelps. ${ }^{1}$ These models deal primarily with the impact of supply shocks on employment and price levels and give only partial attention to inflation rates and the feedback process. So I extend the models to include what Perry calls a "mainline model" of the inflation process, featuring a price markup equation and a wage-adjustment Phillips curve with both a price-wage and a wage-wage feedback mechanism. ${ }^{2}$ The model is solved to determine the conditions under which accommodating and nonaccommodating re-

1. Robert J. Gordon, "Alternative Responses of Policy to External Supply Shocks," BPEA, 1:1975, pp. 183-204; and Edmund S. Phelps, "Commodity-Supply Shock and Full-Employment Monetary Policy," Journal of Money, Credit and Banking, vol. 10 (May 1978), pp. 206-21.

2. George L. Perry, "Slowing the Wage-Price Spiral: The Macroeconomic View," BPEA, 2:1978, pp. 259-91. 
sponses would be appropriate. It is then fitted empirically and simulated in the traditional way to measure the degree of inflation and unemployment generated by various macro strategies in response to a price shock. Because the desirability of these outcomes depends on the relative social costs of inflation and unemployment, I then try to value these relative costs. Some attempts to estimate them based on the work of others are compared with the normative implications of my own model, and with inferences based on survey data. Sensitivity tests are also made to see how the desirability of various strategies is altered when the parameters of the model change and when different conceptions of the social costs of inflation and unemployment are adopted.

Up to this point the model used to analyze price shocks and the simulation of this model are based on relatively standard techniques. To round out the story, I also investigate the question of how supply shocks might be analyzed in some of the newer expectations-oriented theories of the inflation process-the game-of-strategy view of Fellner and the rational-expectations views of Lucas, Sargent and Wallace, Barro, and others. $^{3}$

As a final prefatory comment, I note that the entire paper deals with the macro response to price shocks, with no discussion of how shocks might be prevented from occurring. One conclusion of the paper is that whether shocks generate lingering future inflation or current and future unemployment, they can have large social costs. There would then be great potential gains in any microeconomic supply-management measures that could be designed to prevent shocks, or tax adjustments intended to neutralize their initial impact on overall price levels. But the details of how these measures should be constructed raise issues that are much more industry-specific than are the issues discussed here. Despite their importance, I simply will not address those questions in this paper. ${ }^{4}$

3. William Fellner, Towards a Reconstruction of Macroeconomics: Problems of Theory and Policy (American Enterprise Institute, 1976); Robert E. Lucas, Jr., "Expectations and the Neutrality of Money," Journal of Economic Theory, vol. 4 (April 1972), pp. 103-24; Thomas J. Sargent and Neil Wallace, " 'Rational' Expectations, the Optimal Monetary Instrument, and the Optimal Money Supply Rule," Journal of Political Economy, vol. 83 (April 1975), pp. 241-54; and Robert J. Barro, "Unanticipated Money Growth and Unemployment in the United States," American Economic Review, vol. 67 (March 1977), pp. 101-15.

4. This judgment also partly reflects my view that a good survey of those measures already exists in Robert W. Crandall, "Federal Government Initiatives to Reduce the Price Level," BPEA, 2:1978, pp. 401-40. 


\section{The Theory of Supply Shocks, Price Levels, and Inflation Rates}

Two papers model the relationship between supply shocks and overall output, price, and employment levels. The Gordon model is a two-sector one in which output is exogenous in one sector called the "farm" sector; prices in it are set to equilibrate demand and supply; and overall price and output levels are then determined by the degree of accommodation implicit in the macro policy response. ${ }^{5}$ Phelps' model contains one sector, with the exogenous supply of raw materials as one component of an aggregate production function that has the usual properties of concavity and linear homogeneity. ${ }^{6}$ Gordon considers one case in which prices and wages are perfectly flexible and one in which they are completely inflexible, but the standard case for both models allows for some upward adjustment in aggregate price levels as output and employment increase. Hence the solution of the price and wage sectors of the model (given by the aggregate supply line, $A S$, in the diagram below) is upward sloping. Under Gordon's assumptions, at any level of real aggregate employment, the exogenous decline in farm supplies raises farm and overall prices, hence shifting up the aggregate supply schedule to $A S^{\prime}$; under Phelps' assumptions, the scarcity of materials lowers labor's marginal product and, with a fixed money wage, shifts up marginal costs and prices to $A S^{\prime}$.

The aggregate demand schedule for both models represents the solution of the $I S$ and $L M$ equations and is shown as the downward sloping $A D$ line in the diagram. The standard rationale for this slope is that the nominal quantity of money, $M$, is fixed along the schedule and will support a higher level of aggregate demand for labor when prices, $P$, are lower and the real money stock is greater. This rationale works only when the $I S$ curve is downward sloping and the $L M$ upward sloping. The argument could be made slightly more general and much more realistic by specifying in addition that all government expenditures are indexed but that progressive income tax schedules are written in nominal terms, so that when prices fall, real taxes fall and aggregate demand for labor again increases.

The impact on output and employment of a supply shock in either model is found by shifting the aggregate supply curve as shown, yielding temporarily a positive correlation between inflation $(d P / P>0)$ and un-

5. Gordon, "Alternative Responses of Policy to External Supply Shocks."

6. Phelps, "Commodity-Supply Shock." 
Price level, $P$

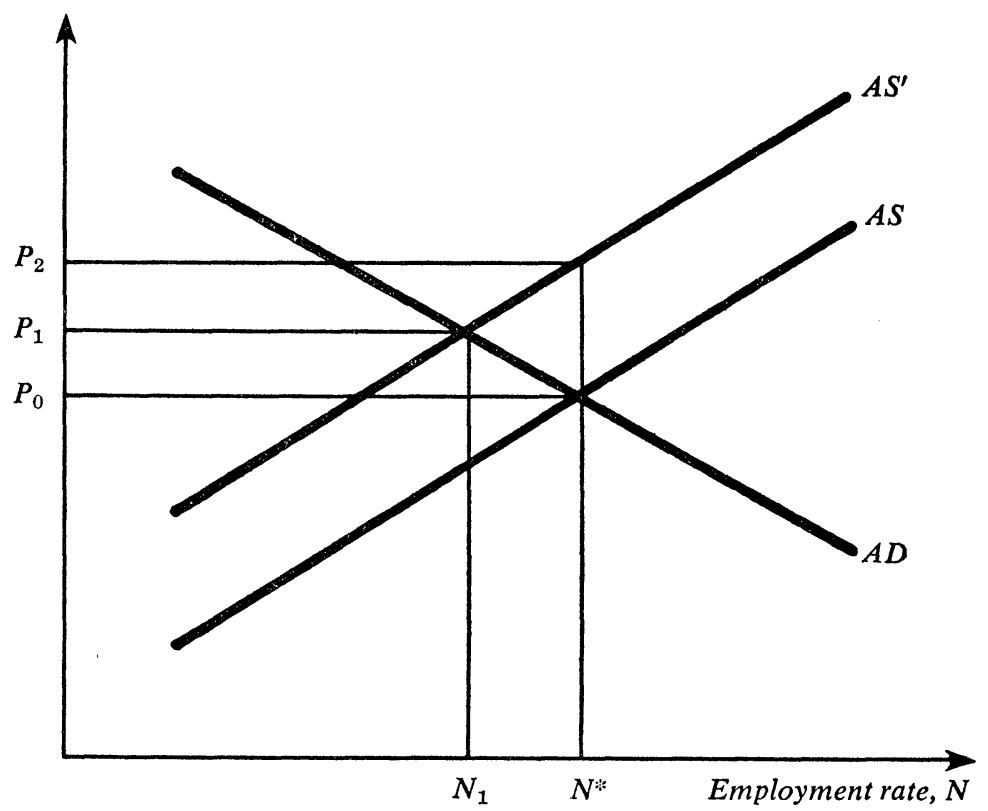

employment ( $N<N^{*}$, where $N^{*}$ is the normal high-employment rate). The new short-run equilibrium will be at $\left(P_{1}, N_{1}\right)$ unless one of several events occurs.

First, there could be an endogenous shift in the $A D$ schedule. The possibility is raised by Phelps, and the shift could be either upward (limiting the employment decline but raising the price level further) or downward (magnifying the employment decrease but limiting the price increase). An upward or outward shift can result because the marginal and average products of labor are reduced by the materials shortage; full employment output is reduced; and thus the money demanded at full employment may be reduced. A downward or inward shift can occur because the shortage of materials also reduces the marginal product of capital and real interest rates, hence tending to raise money demand at full employment. It is difficult to tell which effect will predominate, but using reasonable values of money-demand elasticities, Phelps establishes that there will be some reduction in employment and increase in the price level - that is, any vertical upward shift of the $A D$ schedule will be less than that of the $A S$ schedule.

Second, policy could accommodate the shocks by shifting the $A D$ 
schedule sufficiently to maintain $N=N^{*}$, in the process raising prices to $P_{2}$.

Third, the initial change in prices in any of these scenarios could engender expectations of further changes, hence superimposing dynamic inflationary reactions on the comparative static model. To deal with this problem it is necessary to combine the Gordon-Phelps analysis with an explicit model of the inflationary process. Initially I use the standard or mainline view, in which wage setters agree on their contracts in an economic environment characterized by a state of demand in the labor market and a history of past rates of increase of both wages and prices. There is broad agreement that the inverse function of the unemployment rate, $U^{-1}$, serves well as the demand proxy, but not much agreement about how or why the past rates of wage or price increases should enter the analysis. The standard textbook treatment introduces these terms through an adaptive expectations process: workers base wage behavior on some notion of expected price changes, which are in turn related to past price changes. In contrast, Perry views the process in terms of inertia and catch-ups of wages and prices. ${ }^{7}$ Nor is there agreement on whether the increases to which money wages are responding are those of prices, as in the more common view of the world that invokes cost-of-living escalation, or other wages, as in the view described by Hall, which assumes a competitive labor market. ${ }^{8}$

Without taking sides, it is possible to write an expression for a generalized expectations or inertia Phillips curve incorporating both a pricewage and a wage-wage feedback mechanism,

$$
w=a_{0}+a_{1} U^{-1}+a_{2} L(w)+a_{3} L(p)
$$

where $p$ and $w$ refer to the percentage rate of change of prices and wages, respectively, and the $L$ operator signifies some distributed lag on previous changes. This model implies a short-run trade-off between unemployment, $U$, and inflation, but a long-run trade-off if the sum of the expectationsinertia coefficients $a_{2}+a_{3}$ is unity and if these wage changes are fully passed through into price changes.

For the price equation, the standard model implies that prices are determined by a proportionate markup over costs. To address the issue of

7. Perry, "Slowing the Wage-Price Spiral."

8. Robert E. Hall, "The Process of Inflation in the Labor Market," BPEA, 2:1974, pp. 343-93. 
the extent to which exogenous increases in materials costs are passed through into the inflation process, the expression is written

$$
p=a_{4}+a_{5} w+a_{6} p_{c},
$$

where $p_{c}$ is the exogenous percentage rate of change of materials prices and $a_{4}$ is the negative of the percentage rate of increase of output per factor unit (labor plus materials). Measures for indirect taxes and the cost of capital goods are omitted for the sake of simplicity: if they change proportionately with wages and materials prices, $a_{5}+a_{6}$ should equal unity; otherwise the sum of $a_{5}$ and $a_{6}$ should be less than unity. ${ }^{9}$ While $p_{c}$ is the only explicit supply-shock term in the equation, it should be understood that any shift in the expression, say through a productivity slowdown, will have a similar impact on inflation and unemployment and the response should be the same as it would be for a shock.

The model can be solved by substituting equation 1 into 2 and solving recursively backward. Two assumptions can be made about $p_{c}-$ either that the entire rate of change of materials prices is exogenous, or that only the relative rate of change of materials prices, $p_{c}^{\prime}$, is exogenous, where $p_{c}=p+p_{c}^{\prime}$. Taking first the latter assumption, and assuming in addition that lags in the wage equation last one period, that $a_{2}+a_{3}<1$, and that $a_{5}+a_{6}=1$, yields an expression for the reduced-form inflation equation:

$$
\begin{aligned}
p= & \frac{a_{4}\left(1-a_{2}\right)+a_{0} a_{5}}{a_{5}\left(1-a_{3}-a_{2}\right)}+\left(\frac{1-a_{5}}{a_{5}}\right) p_{c}^{\prime} \\
& +a_{3}\left(\frac{1-a_{5}}{a_{5}}\right) \sum_{i=1}^{\infty}\left(a_{3}+a_{2}\right)^{i-1} p_{c-i}^{\prime}+a_{1} \sum_{i=0}^{\infty}\left(a_{3}+a_{2}\right)^{i} U_{-i}^{-1} .
\end{aligned}
$$

As $a_{2}+a_{3}$ approaches unity, so that the long-run unemployment-inflation trade-off vanishes, any previous level of $U$ will have some impact on the current inflation rate. Moreover, if there is some price-wage feedback mechanism $\left(a_{3}>0\right)$, any previous price shock will lead to some current inflation. But if either of these conditions is not fulfilled, the inflationary impact of price shocks will gradually diminish. These shocks will alter inflation rates in the short run, but they will not do so in the long run. Exactly how long the inflationary impact of a shock will persist then becomes an empirical question depending on $a_{2}$ and $a_{3}$.

9. In Gordon's most recent estimate of his structural price equation, the terms I have omitted did not have statistically significant coefficients. See Robert J. Gordon, "Can the Inflation of the 1970s Be Explained?" $B P E A, 1: 1977$, pp. 253-79. 
The second way to solve the model is to take the entire rate of change of materials prices, $p_{c}$, as exogenous. The equation becomes

$$
\begin{aligned}
& p=\frac{a_{4}\left(1-a_{2}\right)+a_{0} a_{5}}{1-a_{5} a_{3}-a_{2}}+\left(1-a_{5}\right) p_{c} \\
& +\left(1-a_{5}\right) a_{5} a_{3} \sum_{i=1}^{\infty}\left(a_{5} a_{3}+a_{2}\right)^{i-1} p_{c-i}+a_{5} a_{1} \sum_{i=0}^{\infty}\left(a_{5} a_{3}+a_{2}\right)^{i} U_{-i}^{-1} .
\end{aligned}
$$

The condition for the long-term trade-off to vanish and for shocks to persist now becomes $a_{5} a_{3}+a_{2}=1$. Because $a_{5}$ will undoubtedly be close to unity, no large practical difference exists between this form of the solution and that given in equation $3 \mathrm{a}$, but in this solution the price-wage feedback coefficient $\left(a_{3}>0\right)$ now has two effects. In addition to providing the vehicle for shocks to be incorporated into the inflationary process, it also makes the model slightly less accelerationist because now wage changes are slightly diluted every time they feed through the price equation and then back into further wage changes. If the feedback mechanism were of the wage-wage variety $\left(a_{2}=1, a_{3}=0\right)$, this dampening would not exist and the model would remain accelerationist even for $a_{5}<1$.

Equation $3 \mathrm{a}$ or $3 \mathrm{~b}$ provides the reduced-form solution of the price-wage sector. The next task is to use these equations to find the optimal policy response to a shock. This is done by finding the minimum value for the loss function,

$$
S C=\sum_{i=0}^{t}\left(\frac{1}{1+r_{p}}\right)^{i} p_{i}+b \sum_{i=0}^{t}\left(\frac{1}{1+r_{u}}\right)^{i} U_{i}
$$

where $S C$ is social cost; $t$ is the policymaking horizon; $r_{p} i$ s the social discount rate used to value future inflation; $r_{u}$ is that rate used to value future unemployment (not necessarily the same discount rate); and $b$ is the allimportant parameter representing the social cost of unemployment relative to that of inflation.

The optimal response to a price shock can be found by substituting either of the reduced-form expressions, say equation $3 \mathrm{a}$ into 4 , taking derivatives with respect to unemployment (the variable most directly controlled by macro policy), and solving the model. If the policy horizon is assumed to be infinite, this procedure yields a set of equations of the form:

$$
\begin{aligned}
U_{0} & =\sqrt{\frac{a_{1}\left(1+r_{p}\right)}{b\left(1+r_{p}-a_{2}-a_{3}\right)}} \\
U_{i} & =U_{0} \sqrt{\left(\frac{1+r_{u}}{1+r_{p}}\right)^{i}} \quad \text { for } i=1, \ldots \infty .
\end{aligned}
$$


In this solution, the general level of all unemployment rates depends positively on the short-run impact of unemployment on inflation, $a_{1}$, and negatively on the relative social cost of unemployment, $b$. Even if the model is accelerationist $\left(a_{2}+a_{3}=1\right)$, the presence of discounting will yield a general analytic solution for the unemployment path..$^{10}$ And as long as the discount rates are the same $\left(r_{u}=r_{p}\right)$, the optimal path implies that all unemployment rates are the same-that is, that shocks are to be fully accommodated. Macro policy should move the unemployment rate to its optimal level (the nonaccelerating-inflation rate of unemployment in the accelerationist case) and hold it there, with or without shock.

The question of whether or not to accommodate the shock then becomes interesting whenever any of the assumptions of this simple exercise are not fulfilled:

First, if the policy horizon is not infinite but finite, it will be desirable to eliminate the shock-induced inflation before some arbitrary date. In this case, because the inflation-fighting impact of unemployment in the near term is more valuable, there should be a temporary recession, and the shock will not be fully accommodated. ${ }^{11}$

Second, if the relative cost of unemployment, $b$, declines as inflation rises, a shock will raise the optimal unemployment rate at the time it occurs, again implying a less than fully accommodating policy.

Third, if any parameters of the model are not constant but depend either on the state of the economy or some perception of government policy, nonaccommodative responses may become optimal.

And fourth, if the economy was initially in a state of overemployment, a shock could trigger an adjustment to a new higher unemployment rate and appear to signal a nonaccommodative policy response.

The next sections of the paper investigate these matters.

\section{A Standard Empirical Model of the Inflation Process}

I begin by fitting a standard model of the inflation process. The model contains four sections. The first uses standard formulations of wage and

10. Modigliani and Papademos also discuss this issue; see Franco Modigliani and Lucas Papademos, "Optimal Demand Policies against Stagflation," Weltwirtschaftliches Archiv, vol. 114 (December 1978), pp. 736-82.

11. This is the same principle expressed in my previous work; see Edward M. Gramlich, "The Optimal Timing of Unemployment in a Recession," $B P E A, 1: 1975$, pp. 167-80. 
price adjustment to determine the past historical relationship between inflation and unemployment; the second estimates, in several different ways, the key relative cost parameter in the social loss function; and the third estimates the apparent serial correlation, if any, of price shocks. The final section of the model, consisting only of identities, shows how the various accommodating and nonaccommodating policy responses are to be defined.

\section{THE INFLATION-UNEMPLOYMENT RELATIONSHIP}

The standard mainline model of the inflation process features a Phillipscurve wage equation similar to equation 1 and a price markup equation similar to 2 . Both are fit to annual data over the 1954-77 period. Beginning with the former, I define $w$ as the percentage change in average hourly earnings adjusted to exclude overtime and interindustry shifts, $U$ as the unemployment rate using constant (1966) wage-weighted demographic proportions of the labor force, and $p$ as the rate of inflation in the consumer price index. The equation is

$$
\begin{aligned}
& w=-0.394+6.895 U^{-1}+0.3189 p_{-1} \\
& (-0.4) \quad(3.4) \\
& +0.4041 w_{-1}+0.1347 w_{-2} \text {, } \\
& \text { (1.7) } \\
& \text { (0.7) } \\
& \bar{R}^{2}=0.834 \text {; Durbin-Watson }=1.74 \text {; standard error }=0.675 \text {. }
\end{aligned}
$$

The figures in parentheses here and in subsequent equations are $t$-statistics.

This equation is quite similar to that estimated by Perry for the precontrols period..$^{12}$ Adding the last six years of turbulent data has succeeded in lowering the unemployment coefficient only slightly, and has raised the price-wage feedback coefficient from Perry's 0.21 to 0.32 . The cyclical influence of unemployment on wage changes is similar to that found in most wage-adjustment equations estimated in the past decade. Also, as is common currently, the model is nearly accelerationist, with the feedback coefficients summing to 0.86 , slightly more than one-third of which is attributable to cost-of-living escalation and the remainder to wage catch-up escalation. Dummies for the controls period and a post-controls catch-up

12. Perry, "Slowing the Wage-Price Spiral," p. 277, equation 3. In both this equation and in 2 ', I use one hundred times the change in the natural log of a variable as its percentage rate of change. 
were tried in other versions of the equation and did not change the results greatly, with one important exception. There is some collinearity between the catch-up dummy (with a value of one in 1974 and 1975) and the lagged price-inflation term, for the obvious reason that the post-controls period was the one historical episode in which the growth of prices differed markedly from that of wages. When this catch-up dummy is included, the price-wage feedback coefficient drops to 0.11 , below Perry's value of 0.21 . In addition to the usual types of uncertainties, then, there is the specific possibility that the price-wage feedback coefficient could be well below 0.32 , a possibility I will deal with below.

This expression is then combined with a price markup equation along the lines of equation 2. The model is not as elaborate as that estimated by Gordon because I omitted his indirect tax, capital cost, and cyclical terms. (I tried the last, but found them to have the wrong sign.) To simplify this analysis, the price equation is fit with average hourly earnings as the independent variable and the consumer price index as the dependent variable. It would have been more appropriate to use labor compensation (including fringe benefits) as the independent variable and the nonfarm deflator as the dependent variable, but the errors introduced by my simplification seem modest and can be adjusted for. The variable used for the materials price change is the component of the producer price index called "crude materials for further processing"- $\mathrm{a}$ weighted average of the price index for foodstuffs and feedstuffs (with an official weight as of December 1978 of 0.59 ), fuel (weight $=0.15$ ), and other nonfood materials (weight $=$ 0.26 ). When equation 2 was fitted in unconstrained form with the lagged dependent variable to allow for a delayed response, the sum of the longrun coefficients $a_{5}$ and $a_{6}$ exceeded unity, an inadmissible result. So the equation was reestimated with the long-run coefficients constrained to sum to unity by subtracting $p_{-1}$ from the other variables; it also includes dummies for controls, $D_{71,72}$, and post controls, $D_{74,75}$, periods. These had highly significant impacts and this time did not distort the other coefficients in the equation. The equation is

$$
\begin{aligned}
\text { (2') } p-p_{-1}= & -1.207+0.6632\left(w-p_{-1}\right)+0.0953\left(p_{e}-p_{-1}\right) \\
& (-3.8) \quad(5.5) \quad(4.0) \\
& -1.210 D_{71,72}+2.753 D_{74,75}, \\
& (-2.1) \quad(4.5) \\
\bar{R}^{2}= & 0.777 ; \text { Durbin-Watson }=1.61 ; \text { standard error }=0.753 .
\end{aligned}
$$


The productivity trend is 1.21 percent per year; the fit is reasonably good; and the price index for crude materials is highly significant. Solving for the long-run coefficients of $w$ and $p_{c}$ yields values of 0.874 and 0.126 , respectively.

The implications of this two-equation model can best be summarized by solving the equations together and finding the implied long-run inflationunemployment relationship. After a slight adjustment in the constant to account for the fact that the consumer prices rise on average 0.2 percent a year more rapidly than the nonfarm deflator and that gross compensation rises on average 0.4 percent per year more rapidly than average hourly earnings, the long-run equations are

$$
p=-10.77+48.46 U^{-1}+0.4655 p_{c}^{\prime},
$$

when relative crude prices are exogenous, and

$$
p=-7.28+33.06 U^{-1}+0.3177 p_{c},
$$

when absolute crude prices are exogenous,

where $p_{c}^{\prime}$ and $p_{c}$ are now to be interpreted as trend rates of change in relative or absolute prices of crude materials. ${ }^{13}$

The stable-price unemployment rate, $U^{*}$, is found to equal 4.5 percent in both equations; this is slightly more than the average value of 4.1 percent over the 1954-77 period and corresponds to a noninflationary official unemployment rate of 6.2 percent in 1978 , which is approximately what other investigators such as Hall, Modigliani and Papademos, Wachter, and Cagan have found. ${ }^{14}$ At this unemployment rate, a one percentage point

13. The constant adjustment is derived as follows. The equation that should be fit is $p_{n}=\alpha_{0}+\alpha_{1} w_{c}+\alpha_{2} p_{c}$, where $p_{n}$ is the rate of change of the nonfarm deflator, and $w_{c}$ is that of gross compensation. During the period, $w_{c}=w+0.4$ and $p=p_{n}+0.2$. Substituting yields $p-0.2+\alpha_{0}+\alpha_{1} w+0.4 \alpha_{1}+\alpha_{2} p_{c}$. Therefore $0.2+0.4 \alpha_{1}=0.2+(0.4)(0.87)=0.55$ is added to the constant in the consumer price, average hourly earnings equation. This value should be subtracted from the constant of equation $2^{\prime}$ to find the unemployment rate at which an equation of $p_{n}$ on $w_{c}$ would show stable prices, and at which equation 2 ' would show prices rising at 0.55 percent a year.

14. See Hall, "The Process of Inflation"; Modigliani and Papademos, "Optimal Demand Policies"; Michael L. Wachter, "The Changing Cyclical Responsiveness of Wage Inflation," BPEA, 1:1976, pp. 115-59; and Phillip Cagan, "The Reduction of Inflation and the Magnitude of Unemployment," in William Fellner, ed., Contemporary Economic Problems (American Enterprise Institute, 1977), pp. 15-52. 
rise in unemployment would lower the inflation rate by 0.2 percentage point in the first year, a flat short-run trade-off relationship with a slope somewhat below what other investigators have found, but certainly not outside the range of estimates of values of this parameter. ${ }^{15}$

\section{THE SOCIAL COSTS OF INFLATION AND UNEMPLOYMENT}

The various social costs of inflation and unemployment have been enumerated many times. ${ }^{16}$ Inflation generates information costs, efficiency costs, and distributional losses that are especially serious for the aged; unemployment implies an output and income gap that may disadvantage all income groups but is particularly harmful to those with lower incomes. But to analyze policy choices in the presence of price shocks, it is necessary to know more than that both unemployment and inflation entail soeial costs-in particular, how great are these relative costs in quantitative terms?

The literature on program evaluation suggests many ways to answer such a question. A first method might be called the revealed preference technique. As applied to this problem, the reasoning would be as follows. If there is a nonvanishing long-run trade-off relationship, policymakers have already had to select a point on the trade-off curve, and the slope of the curve at that point can be examined to find the implicit marginal rate of substitution of policymakers. The trade-off in the above model is just barely nonvanishing, perhaps by enough to make such a comparison possible. While the weighted unemployment rate (and implicit point of tangency) has varied, it has averaged 4.1 percent over the 1954-77 period, just slightly below the implied noninflationary rate of 4.5 percent. At $U=4.1$, the implied marginal rates of substitution in the long-run trade-off relationship are given by $48.5 \times 4.1^{-2}=2.9$ when changes in relative crude materials prices are exogenous, and $33.1 \times 4.1^{-2}=2.0$ when changes in absolute crude prices are exogenous. Both tangency solutions are shown in figure 1 . Hence this revealed preference method sug-

15. See Arthur M. Okun, "Efficient Disinflationary Policies," American Economic Review, vol. 68 (May 1978, Papers and Proceedings, 1977), pp. 348-52.

16. Most recently by Gardner Ackley, "The Costs of Inflation," and Martin Feldstein, "The Private and Social Costs of Unemployment," in American Economic Review, vol. 68 (May 1978, Papers and Proceedings, 1977), pp. 149-54, and 155-58, respectively. 
Figure 1. The Long-Run Phillips Curve and Optimal Inflation-Unemployment

\section{Combination}

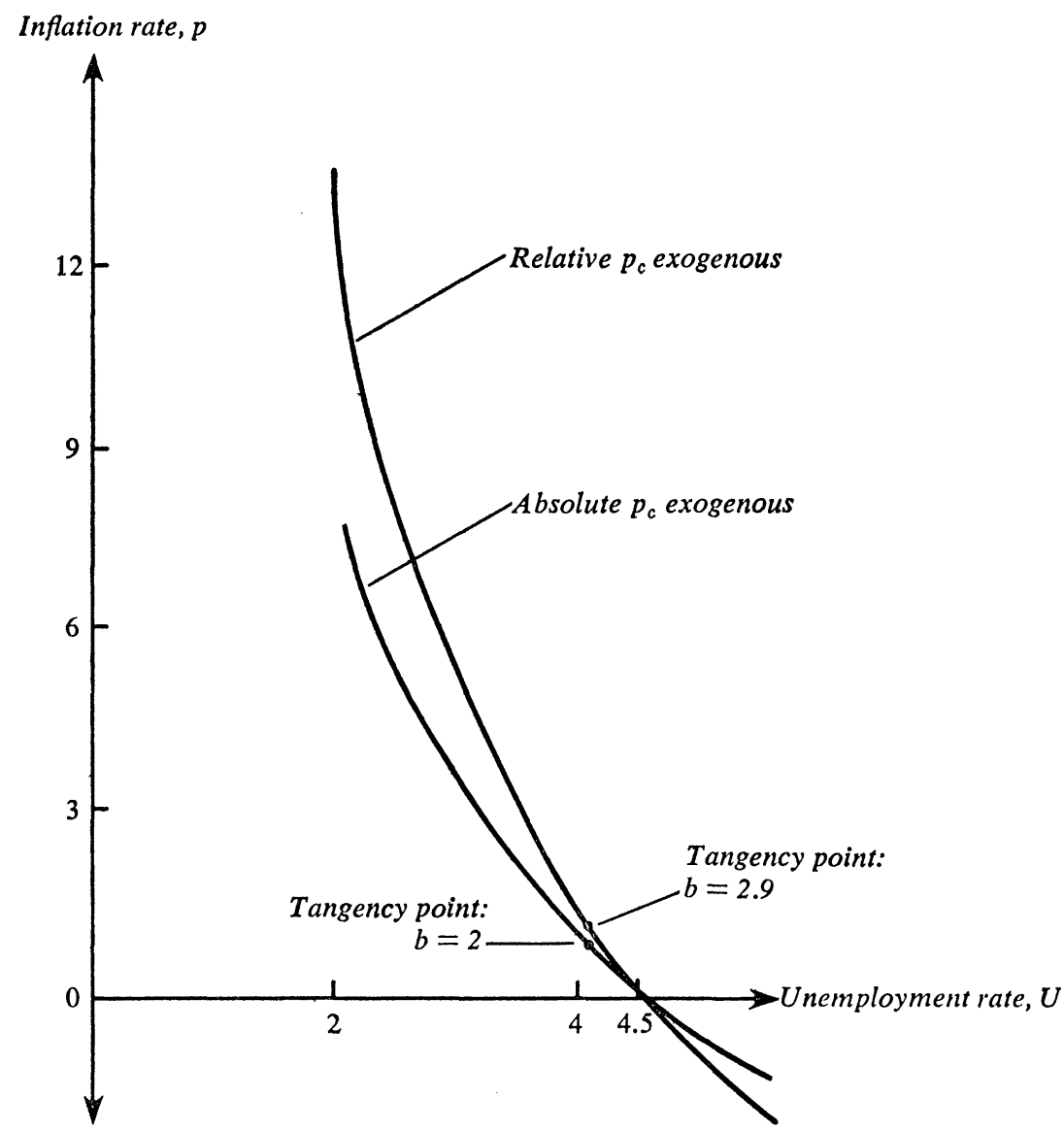

Source: Derived by solving text equations $1^{\prime}$ and $2^{\prime}$ for the implied long-run inflation-unemployment relationship and adjusting for the greater average increase in consumer prices relative to the nonfarm deflator and gross compensation relative to average hourly earnings, as described in text note 13 .

The $p_{c}$ term is the trend percentage rate of change in the absolute price of crude materials; $p_{c}^{\prime}$ is the trend rate of change in the relative price of crude materials, or $p_{c}-p ; b$ is marginal rate of substitution between unemployment and inflation or, alternatively, the relative social cost of unemployment.

The tangency points determine the optimal long-run trade-off. The figure assumes that policymakers have chosen a trade-off at which the weighted unemployment rate is 4.1 percent, its average over the 1954-77 period. 
gests that an added percentage point of unemployment is between two and three times as costly as an added percentage point of inflation. ${ }^{17}$

A second approach to estimating the relative costs of unemployment and inflation might be called the direct estimation technique. As applied by Modigliani and Papademos, ${ }^{18}$ it involves comparing the costs of the output loss of an added percentage point of unemployment, 3 percent of GNP according to Okun's law, with the costs of an added point of inflation. To compute the last, they deal with only the asset transfer costs of inflation, those representing transfers from creditors when actual inflation rates exceed those anticipated at the time financial contracts were signed. Modigliani and Papademos ignore the corresponding gains to debtors by virtue of what might be known as the robbery theorem-robbery is not costless even though it is "only a transfer"; indeed it is at least as costly as the size of the transfer. Because the total value of fixed money claims in the economy is about 1.5 times GNP, a one percentage point rise in the inflation rate lowers the real value of these claims by approximately 1.5 percent of GNP. This yields an estimate for $b$, the relative social cost of unemployment, of $2(3 / 1.5)$, similar to that of the revealed preference value.

The next methods focus more directly on voter preferences. One approach is to use the University of Michigan's index of consumer sentiment to measure the relative unpopularity of inflation and unemployment. Consumption studies by Suits and Sparks, Hymans, and Juster and Wachtel have established that movements in the index can help explain movements in consumption, assuming that consumers feel better off and hence spend more when the index is high. ${ }^{19} \mathrm{~A}$ further analysis by Lovell then shows that movements in the index can, in turn, be explained by stock prices, inflation, and unemployment. The index is lowered by 0.88 point with an additional percentage point of unemployment, and by 1.23 points with

17. Although the social discount rate on inflation should enter into the calculation of the optimum $\left[b=a_{1} a_{5}\left(1+r_{p}\right) U^{-2} /\left(1+r_{p}-a_{2}-a_{3}\right)\right]$, its quantitative impact is small for small values of $r_{p}$. Hence I assumed it to be zero in this calculation and in the figure.

18. Modigliani and Papademos, "Optimal Demand Policies."

19. See Daniel B. Suits and Gordon R. Sparks, "Consumption Regressions with Quarterly Data," in James S. Duesenberry and others, eds., The Brookings Quarterly Econometric Model of the United States (Rand McNally, 1965), pp. 203-23; Saul H. Hymans, "Consumer Durable Spending: Explanation and Prediction," BPEA, 2:1970, pp. 173-99; F. Thomas Juster and Paul Wachtel, "Inflation and the Consumer," $B P E A, 1: 1972$, pp. 71-114. 
an added percentage point of inflation. ${ }^{20}$ Hence the implied value of $b$ is $0.72(0.88 / 1.23)$. Unlike all other techniques, this indirect survey measure weights unemployment less than inflation, and thus even less than it is weighted in the commonly used economic discomfort index (which sums inflation and unemployment rates, thus assuming $b$ is 1 ).

A more direct alternative is to use answers to the Gallup poll question, "What do you think is the most important problem facing the country today?" Households were asked this question twenty-eight times since 1957, and time-series changes in the answering pattern are known to be correlated with actual levels of inflation and unemployment. The basic idea is to explain the percent of households responding that the most important problem was inflation or unemployment with various mathematical constructions of actual inflation or unemployment indicators as independent variables.

In principle there are two ways in which the equations could be fit. One way is in unconstrained form, using as the dependent variable the simple percentage of families responding inflation or unemployment:

$$
\begin{aligned}
& \operatorname{Pr}(p)=f\left(p^{e}, p-p^{e}, U-U^{*}, U U^{*}\right), \\
& \operatorname{Pr}(U)=f\left(p^{e}, p-p^{e}, U-U^{*}, U U^{*}\right),
\end{aligned}
$$

where $\operatorname{Pr}(p)$ and $\operatorname{Pr}(U)$ measure respectively the percent of families responding inflation or unemployment; $p^{e}$, some version of the expected rate of inflation; $p-p^{e}$, the unanticipated rate; $U-U^{*}$, cyclical unemployment; and $U U^{*}$, the official global unemployment rate when the constant-weight unemployment is at its noninflationary value. ${ }^{21}$ This rate in unconstrained form allows implied costs of inflation and unemployment to depend differently on anticipated and unanticipated inflation and cyclical and noncyclical unemployment. Quadratic terms can also be used as needed to test for any nonlinearities in the social cost function.

The problem with the unconstrained technique is that it does not force respondents to trade off inflation and unemployment. Inflation and unemployment are common answers to the question, averaging 28 percent and

20. Michael C. Lovell, "Why Was the Consumer Feeling So Sad?" BPEA, 2:1975, pp. 473-79.

21. Because the constant-weight value of the noninflationary rate is a constant, converting it to an overall basis as shown is the only way I know to allow respondents to express their satisfaction or dissatisfaction with the level of unemployment at full employment. 
10 percent, respectively, of the responses during the period. But they are not the only answers, and to the extent that households change their response to inflation from, say, crime in the streets, the interpretation would be different than if inflation gained at the expense of unemployment. The way to overcome this difficulty is to fit regressions with the dependent variable defined as $\operatorname{Pr}(p) /[\operatorname{Pr}(p)+\operatorname{Pr}(U)]$.

Table 1 provides some illustrative equations, fit first in an unconstrained form, to explain the total percentage of households responding inflation or unemployment. Equations 1-1 through 1-4 explain the percent responding inflation; 1-5 through 1-8, the percent responding unemployment. In table 1 the expected rate of inflation, $p^{e}$, is computed as the average annual rate over the eight quarters before the question was asked, and it can be seen that expected inflation always has a much larger coefficient than unexpected inflation $\left(p-p^{e}\right)$. This could reflect a number of factors-that the households are not yet informed of economists' beliefs that they should already have protected themselves against anticipated inflation; that it may be difficult to protect oneself (for example, many may still be looking for an easy way to save at a positive after-tax real interest rate); that people do not fear something until they expect it; or that I may not have created a good proxy for expected inflation. Whatever the explanation, this particular way of disaggregating the inflation term does not give very sensible results. Hence in all equations except 1-1 and 1-5, I have simply used the contemporaneous inflation rate as the independent variable.

Regarding other aspects of the implied loss function, the unemployment rate at high employment, $U U^{*}$, has a large coefficient in the unemployment equations (equations 1-5 and 1-6), which indicates that trend unemployment is by no means viewed as costless by respondents. The variable has so little variance that its $t$-statistic is usually low, however. When quadratic terms were tried in equations 1-3 and 1-4 for inflation and 1-7 and 1-8 for unemployment, $p^{2}$ and $\left(U-U^{*}\right)^{2}$ invariably took on the wrong sign, indicating that the loss function implicit in these answers does not imply increasing marginal cost as the rate of either inflation or unemployment rises.

The most reliable equations appear to be 1-2 and 1-6. They can be interpreted as follows. Holding unemployment constant, an added percentage point of inflation raises the number of respendents who think that inflation is the nation's most serious problem by 4.14 percentage points 


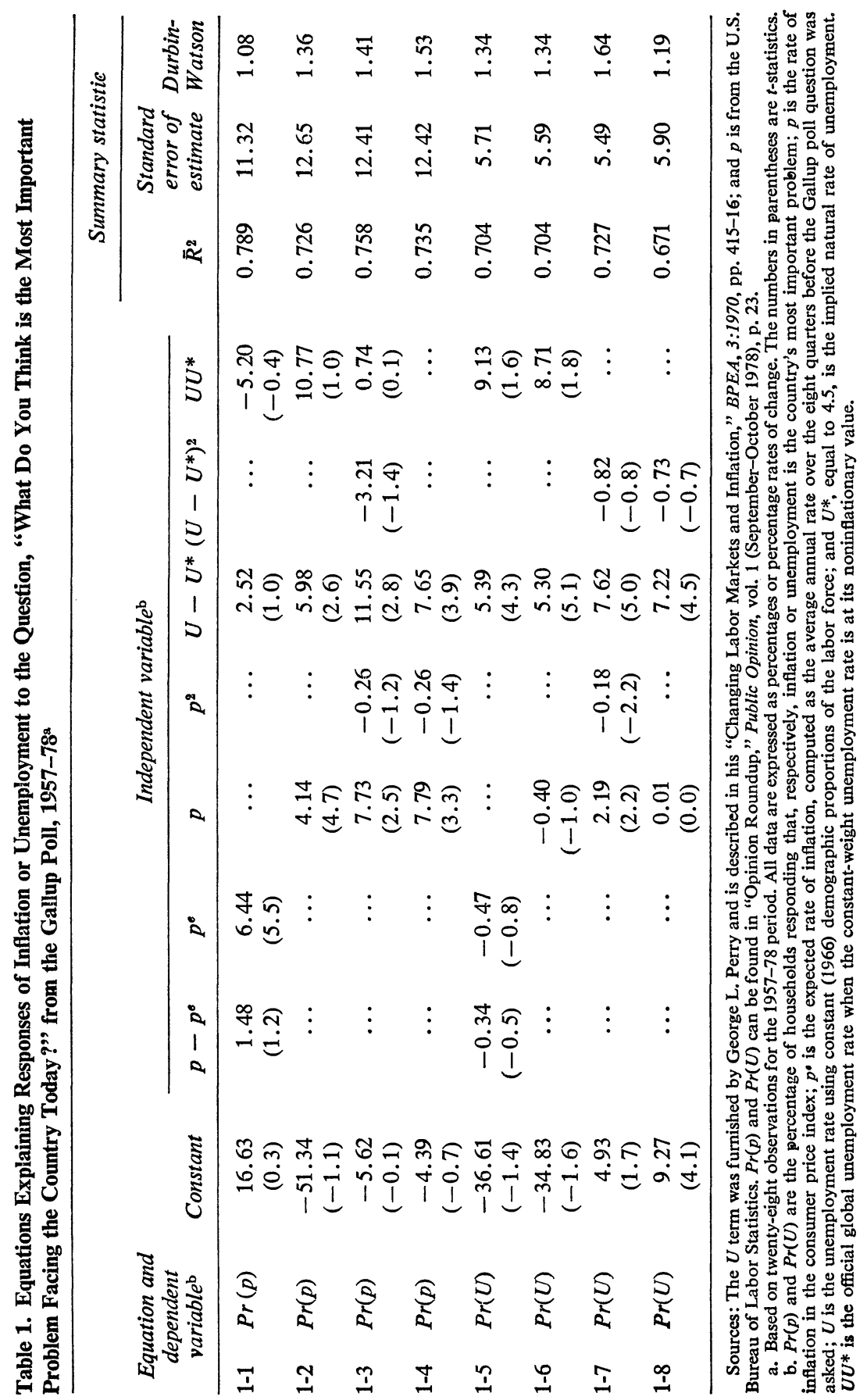


(equation 1-2). Holding inflation constant, an added percentage point of cyclical unemployment $\left(U-U^{*}\right)$ raises the number of respondents who think that unemployment is the nation's most serious problem by 5.30 percentage points (equation 1-6). If social costs increase in some proportion to the number of people whose views about the most important problem are changed, the implied estimate of the social cost of unemployment relative to that of inflation is $1.28(5.30 / 4.14)$. This time the value of $b$ is somewhat greater than unity, but not as high as that given by the revealed preference technique.

Table 2 shows the results when percentages of respondents stating inflation and employment are constrained to add to 100 . Since they do add to 100 , only one type of equation needs to be fit. I fit the one with inflation responses in the numerator, and the implied coefficients for unemployment are the negatives of those in the table. Equation 2-1 of table 2 confirms the above result that expected inflation has a much more adverse impact than unexpected inflation, and in fact this time the latter has the wrong sign. The trend unemployment rate, $U U^{*}$, continues to have the proper sign and a large impact, but is statistically insignificant. Equation 2-2 uses a different variant of the expected inflation rate as the independent variable, simply the nominal interest rate on long-term bonds (assumed to equal $r+p^{e}$, where $r$ is the real interest rate). The results are essentially the same, and unanticipated inflation, while now displaying the proper sign, has a much smaller estimated impact than expected inflation (because the coefficient for $p$ is below that for $r+p^{e}$ ). Equation 2-3 adopts the successful forms of table 1 , and shows that trend unemployment has effectively been eliminated. Equation 2-4, which uses quadratic terms, shows again that both are of the wrong sign. The implied estimate of $b$ in equation 2-3 jumps to $3.96(11.73 / 2.96)$-now a point of unemployment is viewed as nearly four times as harmful as a point of inflation.

There are, of course, serious flaws in all these approaches for measuring $b$. The revealed preference notion depends on my own estimates of the slope of the long-run inflation-unemployment trade-off; it is based on particular historical events such as the Vietnam War, and relies on a very strong assumption of how underlying preferences are reflected in actual policy decisions. The direct estimation approach quantifies only one type of cost of inflation, and very crudely at that. The index of consumer sentiment method is indirect, and it is essentially designed to determine whether households will consume heavily, not to assess perceptions of social prob- 


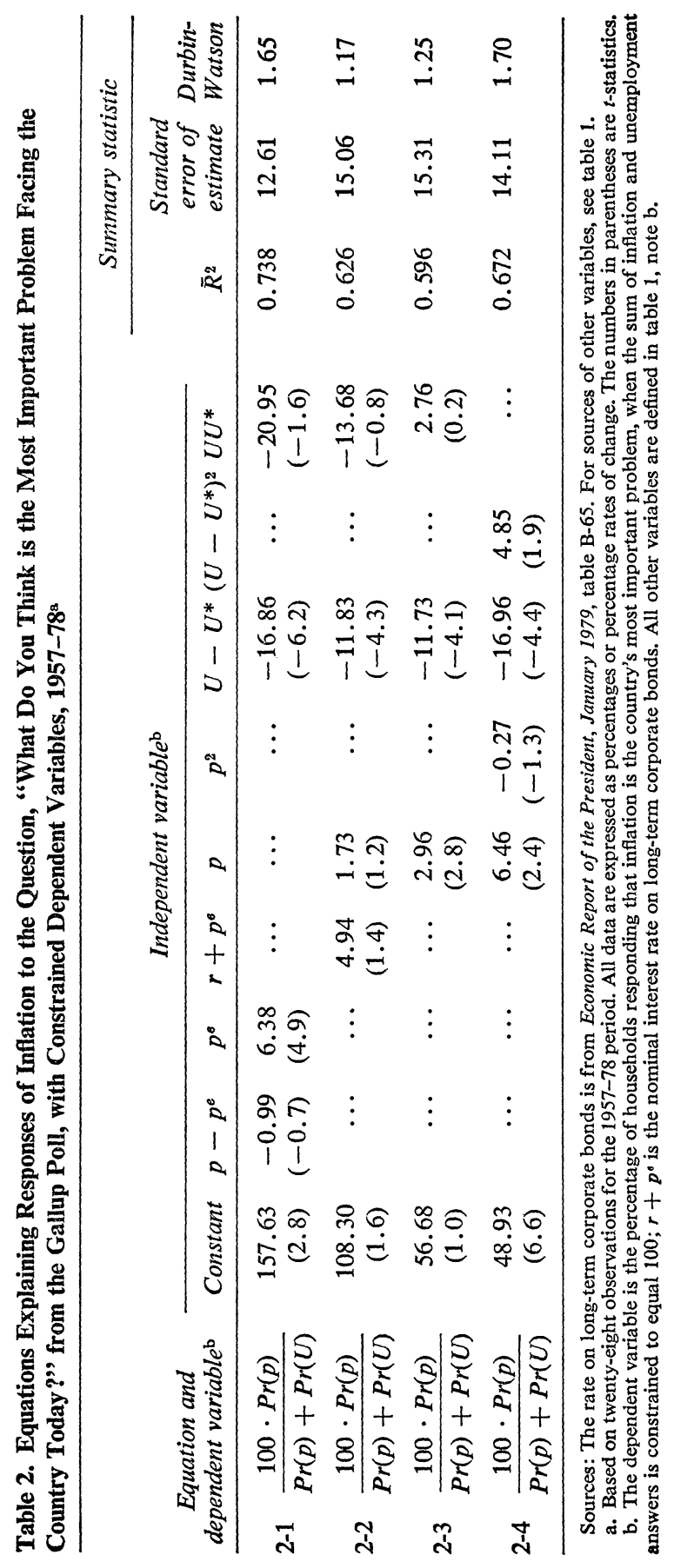


lems. The problem with the Gallup poll methods is that people are not being asked to act on their preferences, only to state them-a well-known and fundamental problem with using survey data. Further, the respondents, like economists, may not understand the nature and seriousness of the inflation problem very well; they may overstate the seriousness if they believe that prices go up because of inflation and that money incomes rise as a result of their hard work. Or they may understate the seriousness because they do not understand the subtleties of efficient resource allocation. Moreover, expectations are relevant. If people, based on historical experience, hold regressive expectations about unemployment and extrapolative expectations about inflation, a rise in the inflation rate will capitalize future fears much more than will a rise in unemployment, overstating the relative costs of current inflation and thus understating $b$. This may also be the reason why expected inflation is considered so painful. Finally, the survey approach does not address the key distributional issue: if either inflation or cyclical unemployment were to be particularly painful to a certain subgroup of the population, as both certainly are, changes in economic conditions may add little to the number of answers in the population at large but a lot to some conception of overall social costs or aggregate pain. About the only point the survey approach has in its favor is that for once social planners are asking people their preferences, not telling them.

Returning now to the question of whether or not to accommodate shocks, if the results of this section can be believed at all, two important implications are that the loss function appears to be approximately linear, with no discernible change in the marginal rate of substitution over observed ranges of variation of inflation and unemployment, and that anticipated inflation appears to be at least as unpleasant to people as unanticipated inflation. The first conclusion tends to support the superiority of shock-accommodating policies, although, as was mentioned above, other conditions must also be satisfied. The second conclusion dictates against an excessive discount of future inflation because it can be anticipated, and tends to lower $r_{p}$ and raise the future costs of any inflation that follows an initial shock.

The more detailed evaluations of various policy responses to price shocks then require quantitative estimates of $b$. These are distributed over a fairly wide range, but it should be somewhat reassuring that quite divergent analytical techniques for measuring them, each one imperfect in its 
own way, gave estimates that were at least halfway consistent. Ranked from low to high, and compared with the economic discomfort index, the estimates are as follows.

\section{Method}

Value of $b$

Index of consumer sentiment (Lovell)

0.7

Economic discomfort index

1.0

Unconstrained Gallup poll (table 1, equations 1-2 and 1-6)

1.3

Direct estimation (Modigliani and Papademos)

2.0

Revealed preference (absolute $p_{c}$ exogenous)

Revealed preference (relative $p_{c}$ exogenous)

2.9

Constrained Gallup poll (table 2, equation 2-3)

4.0

An added percentage point of unemployment appears to be from nearly one to four times as painful as an added percentage point of inflation, with both a median and mean estimate of about two.

\section{SERIAL CORRELATION OF PRICE SHOCKS}

One relatively minor issue that also comes up in the analysis of responses to shocks is the question of serial correlation. When a price shock occurs, is it more likely to reverse itself (as might be the case in Gordon's farm sector) or repeat itself (as with growing scarcities of needed materials)? The issue of serial correlation does not change the underlying analytics in any obvious respect because follow-on shocks can be responded to in the same way as can initial shocks (as long as they remain exogenous ), but still it is interesting to estimate the degree of serial correlation to compute realistic estimates of the amount of inflation and unemployment implied by standard responses to initial shocks.

Beginning with the stochastic part of equations $1^{\prime}$ and $2^{\prime}$, not much evidence seems to exist of either positive or negative serial correlation in the equation residuals themselves. Both equations satisfy the DurbinWatson test for the absence of serial correlation at the 95 percent confidence level.

But the residuals are not the only source of shocks in the model. The other source is the price term for crude materials in equation $2^{\prime}$. The equations in table 3 investigate whether this rate of change is serially correlated by fitting a series of autoregressive equations. Equations 3-1 and 3-2 explain the gross rate of change of crude materials prices, $p_{c}$, 


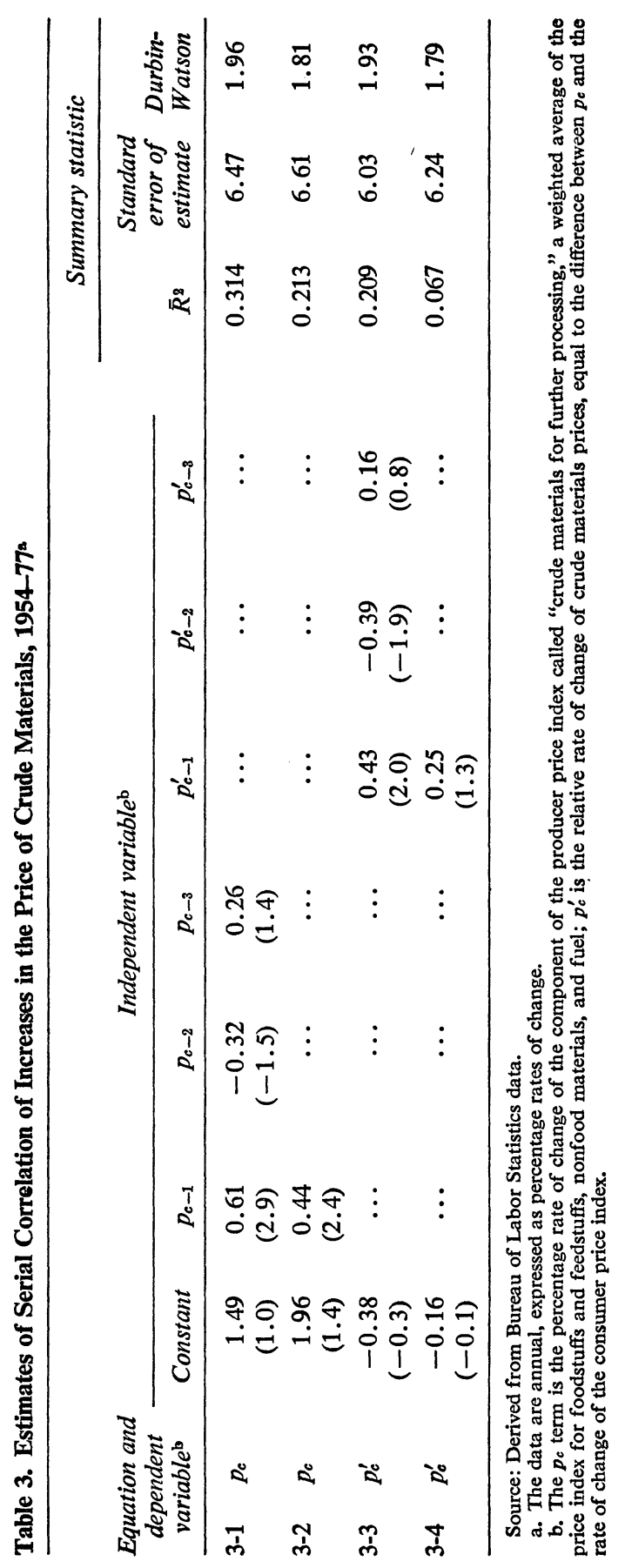


with autoregressive lags up to three years; 3-3 and 3-4 explain the relative rate of change of crude materials prices $\left(p_{c}^{\prime}\right.$, where $\left.p_{c}^{\prime}=p_{c}-p\right)$. Comparison of the two pairs of equations indicates whether or not any endogenous serial correlation component operates through the general rate of inflation.

All equations display reasonably good evidence of some serial correlation. Farm price movements seem to follow a two-year cycle (based on work Saul Hymans showed me from the University of Michigan's econometric model), apparently leading to the negative coefficients for the twoyear lag terms. The one- and three-year lag terms indicate positive serial correlation, suggesting that price shocks generally are not reversed but are augmented by future shocks. Approximately half of this autoregression is eliminated when relative changes in crude prices are used. Whether in absolute or relative terms then, price shocks will be more of a source of continuing inflation, as opposed to one-time increases in price levels, than would at first be apparent.

\section{ACCOMMODATING AND NONACCOMMODATING POLICIES}

To complete the model it is necessary to add some equations to incorporate the government's policy response. At one extreme, if the response were to be complete accommodation of price shocks, such equations would be unnecessary: then the unemployment rate would be held at some predetermined level regardless of any shocks, and the resulting inflation would be given by the wage-price feedback model described in equations 1 and 2 above. Calculations would be just as unnecessary for the other extreme policy of extinguishing price-shock inflation immediately: there the unemployment rate would simply be allowed to rise by the amount appropriate to hold inflation constant. But regardless of the desirability of these strategies, they may not be feasible. By the time a shock is felt, it may be too late to prevent the unemployment rate from rising in a strict accommodation policy, and it will almost certainly be too late to magnify the rise in unemployment under an extreme policy to extinguish inflation. The only realistic approach might be to use some variant of a strategy of nominal income growth, and then more detail in the model is necessary to determine the path to be taken by unemployment and inflation rates.

The most obvious nominal income strategy is the constant growth 
rule-macro policy operates to keep nominal GNP growing at some predetermined rate. ${ }^{22}$ Expressed in percentage changes,

$$
p+y=z,
$$

where $y$ is the percentage rate of growth of real output and $z$ is the predetermined target growth for nominal income. For this paper I do not want to get into the question of whether the authorities must take activist policy measures to keep nominal income growth at rate $z$. I assume that macro authorities can follow such a policy, whether or not the growth of money income is constant automatically.

The other equation relates cyclical changes in the unemployment rate to cyclical changes in real output by Okun's 3:1 relationship,

$$
\frac{Y}{Y^{*}}-1^{*}=-0.03\left(U-U^{*}\right),
$$

where $Y$ is the level of real output and $Y^{*}$ is that at high employment $\left(U^{*}\right)$, assumed to grow at a constant trend rate. Because the growth of nominal income will not be altered in response to a price shock, the shock will first raise $p$ and lower $y$ in equal amounts, resulting in a temporary rise in unemployment by equation 7 . This unemployment will gradually curb the inflation, actually leading in the intermediate run to some overshooting and a reduction in the inflation rate relative to the level prior to the shock. The lower inflation then will lead to higher GNP growth, lower unemployment, and so forth. The process will oscillate to a point at which unemployment returns to its natural rate, GNP grows at its long-run rate, and the inflationary impact of the shock dies out.

The main problem with the constant growth strategy is that the cycles in unemployment may be excessively long. Because prices and wages respond sluggishly to utilization changes in this model, cyclical unemployment persists until the inflation rate declines sufficiently to restore the real growth rate, which may take some years. Particularly when an accommodative policy is optimal, it should be feasible for policy to improve the constant growth outcome. The way to do this would be to introduce a lagged feedback rule, under which the growth of nominal income is set by

$$
p+y=z-\lambda\left(\frac{Y}{Y^{*}}-1\right)_{-1} .
$$

22. As stated in Gordon, "Alternative Responses of Policy to External Supply Shocks." 
When there is underutilization in the previous period, $\left[\left(Y / Y^{*}\right)-1\right]_{-1}$ is less than zero, and the growth of nominal income is raised by some fraction $\lambda$. In this way, persistent cycles in unemployment can be combated, though at the cost of a slower rate of decline of the inflation rate from the initial post-shock level.

\section{Assessment of Alternative Response Strategies}

In this section I use the model described above to estimate the social costs of various policies of response to shocks. Above I showed that, under a set of simplifying assumptions, accommodative policies will in general be preferred: here the approach is to tally up the social costs to measure the margin of superiority, and to observe how this margin changes if some of the simplifying assumptions are relaxed.

The basic approach is to simulate the model in the presence of an assumed price shock. Because it is easier to understand the results if the system is in an optimum position before the shock, I try to place it there. Using the revealed preference assumption and my model precisely as estimated, this preshock equilibrium would be a weighted unemployment rate of 4.1 percent (5.8 percent official rate for 1978). If the trade-off were really vanishing, even though my estimates do not quite suggest that, the preshock optimum would be the nonaccelerating-inflation unemployment rate-the NAIRU - of 4.5 percent. There is obviously not a large difference between the two, but for the sake of argument I followed the natural rate rule and chose the preshock equilibrium of 4.5 percent. At that point the implied value of $b$ in my estimated model is 2.4 (when relative changes in crude materials prices are exogenous).

The results are based on comparisons of the model simulated with 1978 historical values, a control simulation in which the prices of crude materials are assumed to be stable, and a set of experimental simulations in which the prices of crude materials are assumed to rise by 10 percent in year 1, with follow-on shocks as dictated by the serial correlation assumption. Macro policy is assumed to respond according to each of four strategies: complete accommodation, with $U$ remaining at its "optimum" value of 4.5 percent throughout; the lagged feedback nominal income growth policy (equation 8 ); the strategy of constant nominal income growth (equation 6); and complete extinguishing of the shock-induced inflation over a three-year period. 
In each case I compute the difference between experimental and control simulation values for the rate of inflation and unemployment and the discounted sum over an infinite horizon. Three discount rates are tried: zero, as if society's stake in either preserving the value of the dollar or avoiding unemployment were as strong tomorrow as it is today; the "golden rule" rate of 3 percent; and 6 percent, arbitrarily higher than the golden rule rate to approximate what might be the real marginal product of capital. One could also argue (just for inflation) that if any shockcreated inflation is capitalized in future contracts, it entails lower social costs in the future or, effectively, a higher discount rate.

The first set of results is given in table 4. Here no serial correlation of the price increase of materials is assumed and the coefficients of the model are taken as estimated in equations $1^{\prime}$ and $2^{\prime}$. Columns 1 and 2 show the results when the inflationary shock is completely accommodated: the initial impetus declines sharply at first, but after year 4 decays at a much slower rate $\left(a_{5} a_{3}+a_{2}\right.$ from equation $\left.3 \mathrm{~b}\right)$. The cumulated sum of inflation impacts in this case is 3.29 for the one-time increase in materials prices of 10 percent. In columns 3 and 4 at least some rise in unemployment is allowed, and the inflationary impact is less. The closest to the accommodation strategy is the lagged feedback strategy (with $\lambda=1$ ): here the nominal growth in income is adjusted to eliminate utilization gaps in previous years, and some reduction occurs in cumulated inflation and some increase in cumulated unemployment. The strict constant growth rule is shown in columns 5 and 6 , featuring a relatively abrupt decline of inflation but unemployment that persists well past the first five years. The complete extinguishing or "cold turkey" strategy shown in columns 7 and 8 is even more extreme: simply letting unemployment rise the requisite amount to eliminate the inflation over a three-year period. The cumulative unemployment in that strategy is less than that in the constant nominal income strategy because inflation is not allowed to be incorporated into adaptive expectations. ${ }^{23}$

The social costs implied by various strategies appear at the bottom of the table. If $b=2.4$, as would be implied by my price-wage equations if the starting point were an optimum, it can be seen that the accommodative strategy is indeed superior. The social costs that accompany the shock are only slightly higher in the lagged feedback policy, but they approximately double in the strategies in columns 7 and 8.

23. This is the same principle that is illustrated in Gramlich, "Timing of Unemployment in a Recession." 


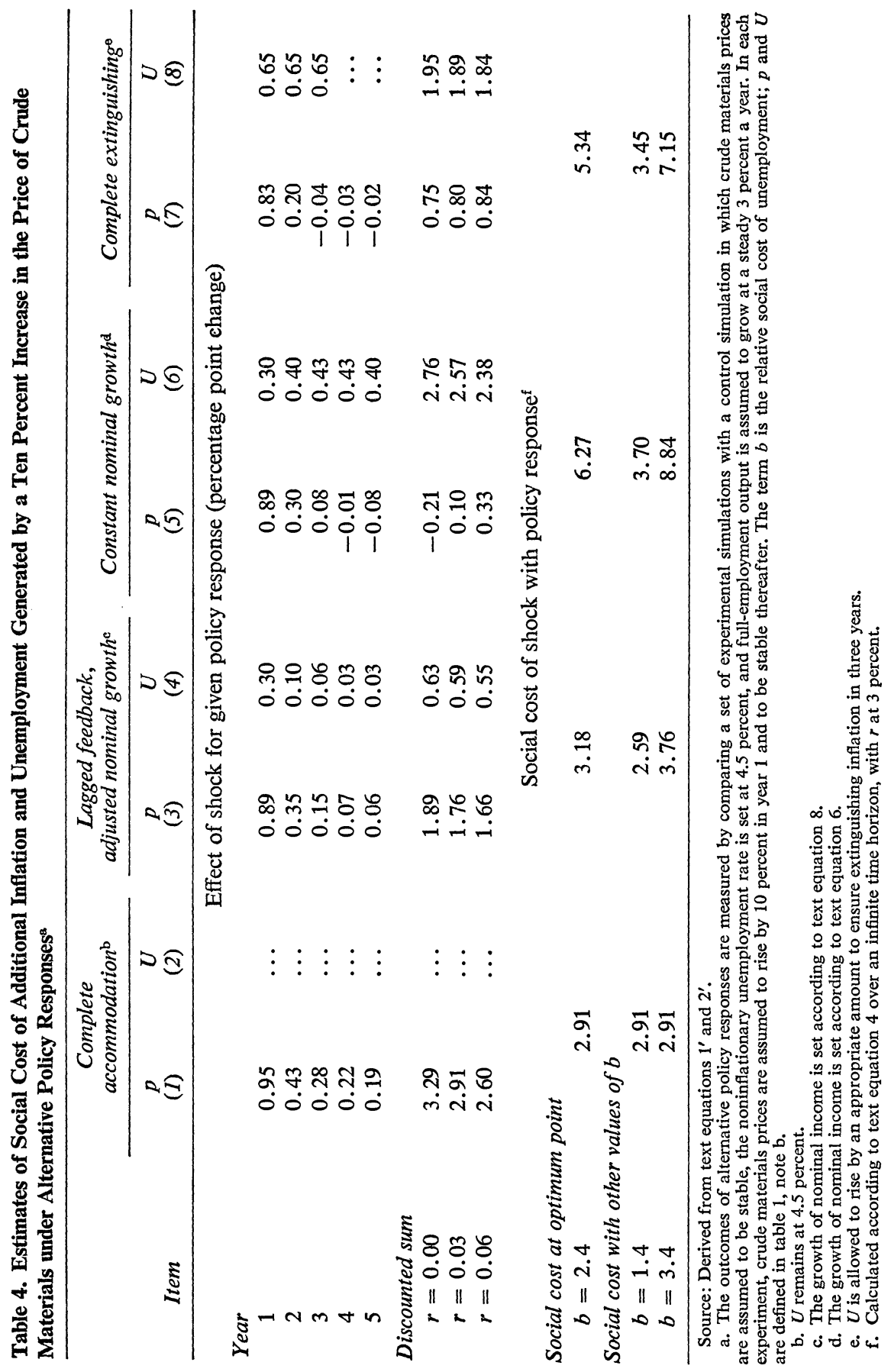


The bottom two lines of the table then conduct sensitivity tests on $b$, using values of 1.4 and 3.4, respectively. The low value of $b$ obviously implies that before the shock the economy should have been operating at a higher unemployment rate to be optimal (assuming my model is correct), and at a lower rate for the higher value of $b$. In the former case, the accommodative policy is no longer optimal, though it is still to be preferred over the nonaccommodation strategies. In the latter case, with a high $b$, the margin of superiority of the accommodation strategy is much greater. Among the lesser conclusions, the lagged feedback rule appears to be a reasonable real world proxy for a perhaps infeasible strict accommodation strategy, and the cold turkey strategy always outperforms that of constant nominal growth. If unemployment is to rise, it is best to take the increase quickly.

The next set of simulations in table 5 is aimed at introducing some technical issues into these calculations. Columns 1 through 4 assume some serial correlation of shocks, with a one-period autoregressive scheme and a coefficient of 0.5 (similar to equation 3-2 in table 3 ). For simplicity, only the extreme accommodation and extinguishing policies are shown. When the shock is accommodated, it can be seen that shock-induced inflation persists much longer, adding to a cumulated sum nearly twice as large as that in table 4 . But because of the nonlinearity in the Phillips curve, unemployment must rise more than twice as much as it did in the simulations of table 4 to extinguish the shock.

Columns 5 through 8 in table 5 move in the other direction. For these the serial correlation is removed and the price-wage feedback coefficient (from equation $1^{\prime}$ ) is lowered to 0.11 -its value when price control dummies are used in the wage change equation-with the difference $(0.32$ -0.11 ) added to the wage-wage feedback coefficient. In this case the inflationary impact of the shock vanishes much more quickly, and the cumulative sum of inflation is cut by about 15 percent; and, again because of the nonlinearity of the Phillips curve, the cumulative sum of unemployment necessary to extinguish the shock is cut almost in half. In this case the strategy of immediately extinguishing the shock narrowly surpasses accommodation when $b=1.4$.

These simulations then generally confirm the superiority of accommodation strategies. When the system is assumed to be near a social optimum before the shock, and under the assumption that my model is correct, accommodation strategies generally entail about half the social cost of 


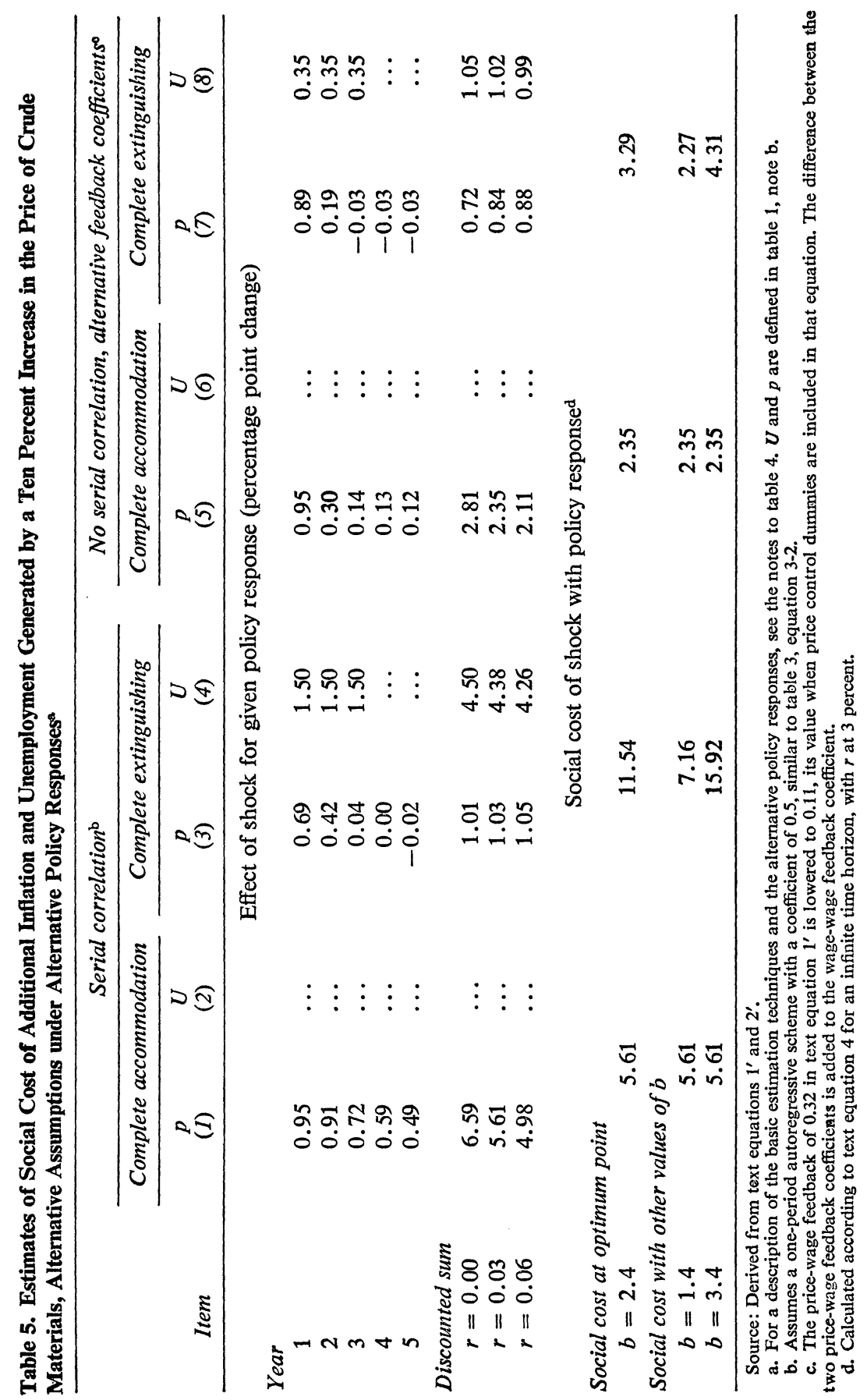


nonaccommodation strategies. If these assumptions are relaxed and $b$ is allowed to take on higher values, this margin of superiority widens. And even when $b$ is allowed to take on lower values, as if the economy should have had a higher unemployment rate all along, the accommodation strategy still compares rather favorably with the nonaccommodation strategies.

\section{The Game-of-Strategy View}

An important potential defect in the foregoing estimation and simulation approach for analyzing responses to price shocks is that it ignores feedback from the economic environment to the coefficients themselves. As a consequence, the standard simulation approach may vastly overstate the social costs of a nonaccommodating policy because it ignores important information about government intentions. One articulation of this idea is implicit in Fellner's game-of-strategy view of the inflation process. ${ }^{24}$ In this view any past inflation data are generated in an environment characterized by a set of measured variables (unemployment rates and so on) and unmeasured variables, such as the perceived view of the private sector on how serious the government is about disinflation. If the government were known to be lax in fighting inflation, private wage and price setters would not reduce wage or price inflation much when unemployment hit-they would wait out the period of unemployment with what appear statistically as sluggish wages and prices. If, on the other hand, they knew that the government meant business about fighting inflation, they would fear losses of jobs and sales from holding to their sluggish wages and prices, and they would reduce inflation more quickly.

The main practical relevance of Fellner's point today lies in the transitional unemployment costs of curing an entrenched inflation: will those costs be small (with Fellner's backbone) or large (as predicted by a standard model such as the one I have estimated)? But the same point also has implications for the response to shocks: the government cannot afford to be accommodative because that would destroy its inflationfighting credibility. If everyone knew that the government would not accommodate shocks, the private sector would not pass them through for the same reason it would not maintain sluggish price and wage re-

24. William Fellner, Towards a Reconstruction of Macroeconomics. 
sponses. Moreover, accommodating any shock opens up a brave new world in which the government can rationalize any inflation by calling it a shock. Finally, accommodation of positive shocks, even if offset by aggregate demand reductions following negative price shocks, will be inflationary on average if more adverse shocks occur than favorable ones (for example, it is normal when Iran is producing oil at full capacity, a shock when that production is below).

At the verbal level, I think, little disagreement would arise with the proposition that expectations of the likely government macro policy response to movements in unemployment and inflation are potentially important in influencing the price and wage change curves. This is presumably why some adherents of the standard model emphasize wage standards, guideposts, and the like. But going from this view to a knowledge of exactly how standard models of the inflationary process must be modified to deal with the phenomenon is a far more difficult step.

In his 1977 article, Fellner himself adjusts the standard model in a rather arbitrary way. His point of departure is Cagan's empirical model of the inflation process, a close cousin of the standard model with three exceptions. Cagan does not disaggregate the process into separate equations for wages and prices, assumes that the model is accelerationist in the long run, fits a parameter representing the speed of adjustment of inflationary expectations, and describes the short-run trade-off relationship as linear. ${ }^{25}$ Rather than measuring the degree of acceleration and the speed of adjustment of expectations, as in the standard model, the Cagan model constrains the former and estimates only the latter. When the standard model is nearly accelerationist, as most are, the properties of both models become similar, though as an empirical matter Cagan does find a greater slope of the short-run Phillips curve than occurs in most standard models. To allow for a credible anti-inflationary strategy, Fellner adjusts Cagan's model by arbitrarily doubling the speed of adjustment of expectations, cutting approximately in half the cumulative unemployment cost necessary to cure inflation. If this procedure were applied to the unemployment impacts of nonaccommodative policies in the simulations of table 4, those impacts might similarly be cut in half, greatly reducing the margin of superiority of the accommodating strategies. If, on the other hand, the policy were accommodative, it would demonstrate

25. Cagan, "The Reduction of Inflation," and William Fellner, "Guide to the Volume," in Fellner, ed., Contemporary Economic Problems, pp. 15-52 and 1-14, respectively. 
customary laxity and no adjustments would be needed in the calculated social costs.

To see whether Fellner has a point in scaling down the costs of a nonaccommodative policy, I first examine the econometric evidence a little more carefully and then discuss an apparently ignored political aspect of the problem. Regarding the econometric evidence, Fellner himself shows great disdain about any econometric evidence taken from periods of policy laxity. But laxity, credibility, and backbone are not mutually exclusive concepts - the government, after all, has always mentioned the goal of price stability, and the government's actions are sufficiently random that some price and wage setters must have believed the government would follow this goal, at least in some past periods. Any recession, and particularly those before inflation accelerated in the midsixties, might therefore be taken as evidence of a government resolve to fight inflation (or an inability to stop cyclical unemployment). If this is so, the standard model should overpredict price and wage increases in all those recessions in which government inflation-fighting resolve is perceived and underpredict when it is not. Because the standard inflation model described above fits the same short-run slope to cyclical movements in the weighted unemployment rate, this test then involves comparing inflation residuals in the early resolve period with the later accommodation period.

These residuals in the five recession years in the 1954-77 sample period are given in table 6. The actual unemployment peak in the 1970-71 period was in 1971 , but because that year was complicated by the pricewage freeze, I used 1970 instead. Column 1 shows the wage-inflation residuals from equation $1^{\prime}$; column 2 , the price-inflation residuals from equation $2^{\prime}$; column 3 , the price residuals corrected for deviations in compensation from average hourly earnings and in the CPI from the nonfarm deflator; and column 4, the simultaneous solution for the corrected price-equation residuals, as if I had calculated a dynamic simulation of the model beginning in the recession year. ${ }^{26}$

26. The corrections are necessary because the compensation index is stochastically related to average hourly earnings, and consumer prices are similarly related to the nonfarm business deflator. I am interested in the residual for the nonfarm deflator as a function of gross compensation. The equation in note 13 gives $p_{n}=\alpha_{0}+$ $\alpha_{1}\left(w_{2}+r_{1}\right)+\alpha_{2} p_{c}$, where $r_{1}$ is the residual of the equation relating rates of change of compensation to average hourly earnings. If $p=p_{n}+r_{2}$, with $r_{2}$ as the residual relating inflation rates, $p=\alpha_{0}+\alpha_{1}\left(w+r_{1}\right)+\alpha_{2} p_{c}+r_{2}$. The correction then involves subtracting $\alpha_{1} r_{1}+r_{2}$ from the $p$ residual. 
Table 6. Residuals from the Standard Inflation Model in Recession Years, 1954-75 a

Percentage points

\begin{tabular}{|c|c|c|c|c|}
\hline \multirow[b]{2}{*}{ Year } & \multirow[b]{2}{*}{$\begin{array}{c}w \\
(1)\end{array}$} & \multirow[b]{2}{*}{$\begin{array}{c}p \\
(2)\end{array}$} & \multicolumn{2}{|c|}{ Corrected $p$} \\
\hline & & & $\begin{array}{c}\text { Single } \\
\text { equation } \\
\text { (3) }\end{array}$ & $\begin{array}{l}\text { Simultaneous } \\
\text { solution } \\
\text { (4) }\end{array}$ \\
\hline 1954 & -0.6 & -0.9 & 0.2 & -0.2 \\
\hline 1958 & -0.5 & 0.2 & -0.3 & -0.7 \\
\hline 1961 & -0.1 & -0.3 & -0.5 & -0.6 \\
\hline 1970 & -0.2 & 1.1 & -0.3 & -0.4 \\
\hline 1975 & 0.6 & -1.0 & -0.3 & 0.1 \\
\hline
\end{tabular}

Source: Text equations $1^{\prime}$ and $2^{\prime}$.

a. The wage, $w$, and price, $p$, variables used in the equations are the percentage rate of change in adjusted average hourly earnings and the consumer price index, respectively. The residuals in column 1 are from text equation $1^{\prime}$ and in column 2, from text equation $2^{\prime}$. Column 3 corrects the residuals in column 2 for deviations in compensation from average hourly earnings and the CPI from the nonfarm deflator, as deseribed in the text, note 26 . Column 4 presents corrected residuals from a simultaneous solution for the price equation residuals, as though a dynamic simulation of the model was conducted beginning in the recession year.

The wage-equation residuals in the first three recessions are indeed negative, indicating some overprediction of wage growth in these inflationresolve periods. These residuals are small relative to the equation's standard error, averaging less than one-half a standard deviation, but sufficiently great that they double the short-run slope of the Phillips curve (averaging 0.4 for 1.5 percentage points of unemployment). The idea also works in the latter two "nonresolve" recessions, underpredicting wage changes by an average of 0.2 percentage point. The illustration is perhaps particularly strong in the 1975 recession, when the government promised an expeditious return to full employment throughout. Hence there is some evidence from these residuals on wage changes that resolve matters.

The signals from the price equation are less clear. Using the residuals from column 3, which are corrected for random blips in the relationship between the CPI and the nonfarm deflator and between gross compensation and average hourly earnings, the price equation is found to overpredict in two of the three early recessions, and both the later ones. The average overprediction in the early recessions is 0.2 , again small relative to the equation's standard error and the residual corrections, but not very small relative to the flat short-run slope of the Phillips curve. When I put these corrected residuals together with the wage residuals by solving the model simultaneously, the result is an average overprediction in the early recessions of 0.5 . Enormous uncertainties exist in all of this, but if a large share of the overprediction can be attributed to Fellner's point, 
his procedure of arbitrarily doubling the short-run slope of the Phillips curve turns out to be a reasonable way to correct the estimates. Adding these adjustments to the simulations of table 4 would indeed approximately cut in half all implied figures of cyclical unemployment cost on the right side of the table.

Turning from this econometric test to a more basic discussion, the idea that private price and wage setters have some idea of how the government will deal with inflation and unemployment is not new and has been discussed many times in both a favorable and an unfavorable light. Without repeating all the points that have been made, I would like to highlight one other aspect of the theory, which to my knowledge has not received extensive discussion. The general point of view of any kind of credibility model of the inflation process is a divergence of interests of the public and private sector. The private sector has one objective (raising wages or prices) and the government has another (holding them down). This sets up the bargaining-perception situation that Fellner emphasizes: if the private sector feels the government has a strong hand, it can be bluffed into less inflationary contracts by the fear of anticipated unemployment once the government plays its cards. But there are at least three distinct problems with the view:

Uncertainty-The view hinges on the assumption that estimated coefficients of short-run Phillips curves will change, a necessarily speculative assertion. If they do not, or do not change much, the temporary unemployment cost may force officials to abandon the strategy and return to high employment.

Horizon-If the temporary unemployment required to root out inflation lasts past the next election, elected officials may not implement policies that improve the nation's welfare (essentially the problem of the political business cycle). In effect, the interest rate relevant for the officials is far higher than the rates used in tables 4 and 5 .

Interest groups-Even if the median voter were convinced that some temporary unemployment was necessary to cure inflation, strong pressure groups may be able to defeat such a policy. As a case in point, George Meany's apparent response to President Carter's new religion about fighting inflation seems more likely to change the identity of the President than the bargaining strategy of the unions.

These criticisms are not necessarily devastating to Fellner's argument because they do not deal with the question: who is to be blamed if private 
price and wage setters do not believe or accept the government's resolve in fighting inflation, and if their actions lead to high unemployment? If somehow the government can establish a position above the fray, it may not be forced to take responsibility for the high unemployment-which followed logically from private actions and from the fact that nobody took the government seriously. But here the Keynesian tradition gets in the way. After three decades of economists' proclaiming that unemployment is not inevitable and can be cured by government macro policies, it will now be difficult for economists to state that unemployment is the fault of the private sector. More realistically, the government will be blamed for high unemployment, just as it often takes credit for high employment.

It then becomes difficult to know how seriously to take Fellner's objection to the standard model, and my objections to his objection. Today it is true that the percent of respondents who answer that inflation is the nation's most important problem is rising daily-as my regressions in tables 1 and 2 predict-and this should give elected officials new resolve in their fight against inflation. Perhaps price and wage setters in the economy will perceive this and respond to expected unemployment with more restraint than they appear to display in response to actual unemployment. But as soon as unemployment rises, the same regressions predict that voters will then begin to fear unemployment also, and that is likely to sap the resolve of officials and leave us with the same old lax policies and the same old flat short-run trade-off curve. In this sense, the ultimate obstacle to accepting the empirical relevance of Fellner's argument may be the seemingly innocuous coefficient of cyclical unemployment in the Gallup poll regressions. Price-setting and wage-setting behavior might not be inflationary if sufficient resolve were shown. But can that ever happen in a democracy where people fear unemployment too, begin to worry about it once it starts rising, and may even blame it on the government?

\section{Rational Expectations}

Fellner's inflation-fighting credibility plays the role of a variable omitted from standard econometric models whose presence would alter the results. A more fundamental restructuring of the standard model has been undertaken by Lucas, Sargent and Wallace, Barro, and others of the rational 
expectations school. ${ }^{27}$ In this section I examine how a rational expectations model treats responses to price shocks.

I begin with three caveats. The first is that the rational expectations model used here is a somewhat generalized version used by Fischer, of which the pure rational expectations model is a special case. ${ }^{28}$ Fischer's model assumes that price and wage setters make rational expectations forecasts when they sign their price-wage contracts, but that once signed, these contracts fix wages and prices over some horizon. ${ }^{29}$ If the contract period is short relative to the inside information lag of the monetary authority, the pure rational expectations result emerges and the optimal rule for monetary policy is simply to let the money supply grow at a constant rate even if policy is concerned with minimizing the variance of cyclical unemployment. But if the contract period is long relative to the inside lag of the monetary authority, the model becomes more Keynesian and the authority should respond to shocks in a way that reflects its view of the social costs of unanticipated inflation and cyclical unemployment.

The second caveat addresses the types of prices incorporated in rational expectations models. All such models explain cyclical unemployment as a negative function of errors in forecasting prices: if prices and wages are lower than anticipated, firms and labor temporarily supply less output and unemployment temporarily rises above its natural rate. Implicit in this behavior is the fact that prices are taken to be the "internal" ones received for sales of goods and services, rather than prices paid to exogenous suppliers. With a supply shock operating in the Gordon-Phelps manner, however, unemployment would increase while prices and wages were higher than expected, violating the usual rational expectations behavior. The best way around this difficulty is to build a rational expectations model with both internal and external prices, letting temporary deviations in aggregate supply depend differently on which type of price is incorrectly predicted. I will not do that, but will reinterpret prices in the rational ex-

27. Lucas, "Expectations and the Neutrality of Money"; Sargent and Wallace, "Rational Expectations"; and Barro, "Unanticipated Money Growth."

28. Stanley Fischer, "Long-Term Contracts, Rational Expectations, and the Optimal Money Supply Rule," Journal of Political Economy, vol. 85 (February 1977), pp. 191-205.

29. Edmund S. Phelps and John B. Taylor have an alternative version of such a model, but it incorporates a whole aggregate demand system and is much more difficult to use. See "Stabilizing Powers of Monetary Policy Under Rational Expectations," Journal of Political Economy, vol. 85 (February 1977), pp. 163-90. 
pectations model as only internal prices, and will discuss qualitatively the types of results that should emerge from such a model.

The third caveat deals with the relationship between aggregate supply and unemployment. The standard rational expectations model treats aggregate supply as fixed, and has actual output vary around aggregate supply according to a set of terms representing unexpected changes in macro policy and a residual. Because supply is fixed and demand variable, the residual is really to be interpreted as a demand shock. But in this paper I am interested in the proper response to supply residuals, and for these it is clear that supply-induced drops in actual output will also lower fullemployment output in the short run, without directly raising unemployment. I deal with this by adding an explicit relationship explaining cyclical unemployment.

The model can be expressed in three equations:

$$
\begin{gathered}
Y=Y^{*}+0.5 c_{1}\left(P-E_{-1} P\right)+0.5 c_{1}\left(P-E_{-2} P\right)+u \\
Y=c_{2} M-P-v \\
U-U^{*}=-c_{3}\left(Y-Y^{*}-u\right) .
\end{gathered}
$$

Here the operator $E_{-i}$ refers to the expectation of a variable made in the $i$ th previous period. Following the usual rational expectations conventions, the entire model is in log form and all variables (except the unemployment rates) are expressed that way. Equation 9 is the modified aggregate supply equation of Lucas, where $Y^{*}$ is defined as the fixed normal long-term level of output and $P$ is defined as the internal price level. Deviations in actual output from $Y^{*}$ are made a positive function of misforecasts in internal prices in $t-1$ and $t-2$, with the $c_{1}$ coefficient giving the implied short-term elasticity. I have formulated the model as if all contracts lasted for two years, so the 0.5 coefficients reflect the proportions of price and wage contracts signed in each year, which incorporate that year's expectations about internal prices.

Equation 10 is an aggregate demand equation that is here made monetarist for simplicity; it would be possible to include fiscal variables in 10, but that would add complexity without leading to any additional insights on how policy should react. Equation 11 then expresses the link between aggregate supply and the cyclical unemployment rate, $U-U^{*}$ (not in log form). Percentage rises in $Y$ above $Y^{*}$ will make cyclical unemployment negative according to the coefficient of Okun's law, $c_{3}$. 
The influence of price shocks of various sorts can then be described in terms of the $u$ and $v$ residuals. Take first the Gordon-Phelps supply shock where farm output is abruptly lowered by a crop failure. This enters the model as a direct reduction in $Y$, or a negative $u$. Its direct influence on cyclical unemployment is neutralized by including $u$ in equation 11 . But there will be an indirect influence on both unemployment and internal price levels working through the $v$ term. If spending demands for farm output are price inelastic, the negative $u$ will raise the money income of the farm sector, raise transactions needs for that sector, and thus imply a positive $v$. If the Federal Reserve does not accommodate these transactions surprises, the negative $u$ must thus lower internal price levels through equation 10.

A second type of price shock could be a pure price disturbance, such as a rise in the price of internationally traded goods. This type of shock will have no direct influence on real output $(u=0)$, but if the demand for imports is price inelastic, it will again raise the transactions demand for money, and imply that $v>0$, thus tending to lower internal prices for a given $M$. Finally, there could be a shock that lowers output without any direct effect on internal prices, say with a drop in productivity or a strike. In this case output is down, $u<0$, but there is no direct effect on velocity and $v$ is equal to zero.

The model can be solved by substituting equations 9 and 10 together to solve for $P$, taking expectations, and inserting the calculated expressions for $\left(P-E_{-1} P\right)$ and $\left(P-E_{-2} P\right)$ back into the expression for $Y$. The reduced-form equation for $Y$ becomes

$$
\begin{aligned}
Y & =Y^{*}+0.5 u-0.5 c_{1} v+\frac{0.25 c_{1}}{1+0.5 c_{1}}\left[c_{2}\left(M-E_{-1} M\right)\right. \\
& \left.+\left(1+c_{1}\right) c_{2}\left(M-E_{-2} M\right)+E_{-1}(u+v)+\left(1+c_{1}\right) E_{-2}(u+v)\right] .
\end{aligned}
$$

This expression can then be inserted into 10 and 11 to obtain the reducedform expression for internal price levels and unemployment. It has the standard rational expectations property that real output equals its trend value, with a series of stochastic terms that were impossible to forecast when price and wage contracts were set, and with two terms referring to surprises in monetary policy. If the Federal Reserve had a one-period inside lag and all contracts had been signed in the previous year (all $E_{-2}$ terms are absent), only unanticipated monetary changes could influence real output-the most well-known rational expectations result. But as 
Fischer showed, if the inside lag is one period and some contracts last for two periods, it is possible even for systematic monetary changes to stabilize output.

Macro or monetary policy is introduced in the model by writing a reaction function for the Federal Reserve. Assuming again that it has a oneperiod inside lag, it can set monetary policy only on the basis of information from the previous period. If there is no serial correlation of residuals, even this is impossible because it has no information about the present period. But if there is serial correlation, an equation expressing the behavior of the Federal Reserve is

$$
M=M^{*}+c_{4} u_{-1}+c_{5} v_{-1},
$$

where $M^{*}$ is a predetermined trend amount and the $c_{4}$ and $c_{5}$ coefficients determine in general how the Federal Reserve should respond to shocks. Using another basic assumption of rational expectations, the private sector can be assumed to know both the Federal Reserve's reaction coefficients and all the information it has; no residual monetary surprises are assumed.

The model can be solved by substituting 13 into 12 and minimizing some loss function of the policymaker. The loss function minimized by Fischer depended simply on the variance of $Y$ around $Y^{*}$, but to preserve the spirit of this paper, I should make it depend on $U$ and also include an inflation term. At that point, some of the simplifications I have made to adjust to the rational expectations model become troublesome. One problem is that the rational expectations loss function includes only unanticipated inflation rates $\left(P-E_{-2} P\right)$ because all anticipated inflation has already been adjusted for in previous price and wage contracts and is therefore costless (an assumption that does not square with my survey results described above). Another serious problem is that the price levels that enter the rational expectations model are only internal prices, and any external inflation is therefore also viewed as costless. This makes no logical sense, so I will not present a formal optimal policy exercise. But it is possible to determine qualitatively how macro policy should respond to shocks in the rational model.

The simplest case is that of a pure quantity disturbance, such as a dip in productivity. In this case $u$ is less than zero, but unemployment does not rise (equation 11). There is no direct effect on internal prices $(v=0)$, but as a result of the drop in $Y$, too much money is chasing too few goods and internal prices are bid up, temporarily lowering unemployment 
through the aggregate supply expression. If the Federal Reserve did nothing, inflation would be up and unemployment down, and both signals would suggest that monetary policy ought to tighten. The implication of such a strategy would be similar to the immediate recession, or cold turkey, policy described for the standard model.

Next, take the case of a pure price disturbance, such as a rise in prices of imports with inelastic demand. As was said above, $v$ is positive and $u$ is zero in such a case. The pure price disturbance raises the overall inflation rate but, because of the positive $v$, internal prices will be lowered and unemployment raised. The optimal monetary response here depends on that great unknown, the social cost of unemployment versus that of inflation. For low $b$ values, the Federal Reserve will tighten or not accommodate; for high $b$ values it will accommodate this type of shock. If the loss function were written solely in terms of internal inflation rates, the Federal Reserve would unambiguously accommodate this shock, showing exactly why that approach is not fruitful.

The last case of a supply shock is the Gordon-Phelps crop failure, the one with which the paper began. Because $u$ changes along with $v$, this case appears to be different from the pure price disturbance, but in fact it is not. The reason is that the $u$ change is neutralized in the unemployment equation, implying no initial rise in unemployment. While it is true that $Y$ drops, as in the case of the quantity disturbance, the fact that demand for farm products is price inelastic assures that internal prices will also drop, and that unemployment will eventually rise by this indirect channel. Hence in this case, as in the standard model, the shock will temporarily increase both overall inflation rates and unemployment rates, and again put the Federal Reserve in the dilemma it has had throughout the paper. It will either accommodate the shock or not, depending on its view of the relative cost of unemployment versus that of inflation.

At this level, then, the rational expectations responses look much the same as those implied by the standard model. One new feature emerges: If the Federal Reserve's inside lag is long relative to the contract period, it should not do anything at all. But otherwise the Federal Reserve will have to choose between inflation and unemployment in the same traditional way. The main difference between the rational expectations model and the standard model is not in the direction of the macro policy response, but in differences in social costs among the various policies.

In the standard model the differences between various policies can in- 
volve substantial amounts of inflation or unemployment, persisting over a substantial length of time. But in the rational model these differences, and indeed the social costs of a shock, are negligible: as soon as last year's round of wage contracts has lapsed, expectations become rational again and past price shocks become irrelevant in determining future levels of both output and prices.

\section{Implications}

Perhaps the most important result of this examination of supply price shocks in the standard model is that whatever the macro response, shocks are very costly. If their unemployment impact is minimized by accommodating policies, the shock-induced inflation can linger for several years. If their inflationary impact is minimized by an immediate recession, the cost in terms of high unemployment is sizable. Various intermediate approaches are possible, but all result in some combination of persistent unemployment, persistent inflation, or both. If nothing else, this dramatizes the need for policies other than macro responses to minimize price shocks.

But it may be that such policies cannot be designed, and that macro authorities will have to live with exogenous price shocks. Then the choice of macro policy responses to shocks cannot easily be divorced from the question of where the economy should have been before the shock. It can be shown theoretically that in a simple model in which the policymaking horizon is infinite, the parameters of both the behavioral model and the social loss function are constant, and optimality was initially achieved, it will be optimal for policy to accommodate the shock and prevent the unemployment rate from changing. Because there appears to be little evidence of shifts either in behavioral or social loss coefficients, that model may be a reasonable first approximation to reality. Accommodation policies are thus likely to be less costly, though by margins that vary from small to large under different interpretations of the marginal social costs of unemployment and inflation. 